\title{
ADOLESCÊNCIA: FENÔMENO SINGULAR E DE CAMPO
}

\author{
Adolescence: a singular and field-related phenomena \\ La adolescencia: un fenómeno único y producidos en el campo
}

LAUANE BARONCELLI

\begin{abstract}
Resumo: O período do desenvolvimento humano denominado adolescência vem sendo frequentemente concebido, tanto na literatura científica sobre o tema, quanto no imaginário do homem comum, de forma estereotipada e generalizante. Condições de caráter histórico e concreto são, nesta ótica, naturalizadas, e a adolescência é tomada como uma série previsível de características comuns a todos aqueles que vivenciam o período. Neste artigo, analiso como e por que a Abordagem Gestáltica questiona e refuta tal perspectiva. Na literatura sobre adolescência, tais questões vêm sendo tradicionalmente discutidas na perspectiva da Psicologia Sócio-Histórica. Por isso, e considerando também a afinidade teórica desta perspectiva com a Gestalt-terapia no que tange à relação indivíduo/contexto, o artigo inicia com uma breve discussão sobre a ótica sócio-histórica acerca da adolescência. Em seguida, analisa-se como a Gestalt-terapia, por meio de seus pressupostos teóricos mais elementares - destacando-se, entre eles, a Teoria de Campo de Kurt Lewin - ressoa e oferece novas nuances à crítica sócio-histórica, concebendo a adolescência como um fenômeno singular e de campo.
\end{abstract}

Palavras-chave: Adolescência; Gestalt-Terapia; Psicologia sócio-histórica; Teoria de campo.

Abstract: The developmental period called adolescence has been often conceived, both in the scientific literature about the subject as well as in common sense, from a stereotyped and generalizing point of view. Historical and concrete conditions are, in this perspective, conceived as natural features of adolescence and the period is taken as a set of predictable characteristics common to all adolescents. In this paper, I analyze why and how the Gestalt Approach refutes this perspective. In the literature on adolescence, these issues have been analyzed on the perspective of the Socio-historical Psychology. As such, and also because of the affinities between this perspective with Gestalt-therapy in regard to the relationship between individual and context, the paper begins with a brief discussion about the socio-historical outlook on adolescence. Following, it is analyzed how Gestalt-therapy, according to its most elementary theoretical premises - foremost among them, the Kurt Lewin's Field theory - resonates and, at the same time, provides new nuances to the socio-historical critique, conceiving adolescence as a singular and field-related phenomenon.

Keywords: Adolescence; Gestalt-Therapy; Socio-historical psychology; Field theory.

Resumen: El período de desarrollo llamado adolescencia a menudo se ha concebido, tanto en la literatura científica sobre el tema, así como en el sentido común, desde un punto de vista estereotipado y generalizado. Condiciones generales de uso histórico y concreto son, en este punto de vista, naturalizada, y en la adolescencia se toma como una serie predecible de características comunes a todos los que experimentan el período. En este artículo se analiza cómo y porqué el enfoque Gestáltico refuta esta perspectiva. en las teorias sobre la adolescencia, estas cuestiones han sido analizadas desde la perspectiva de la Psicología socio-histórica. Como tal, y también debido a las afinidades entre esta perspectiva con la Gestalt-terapia en cuanto a la relación entre el individuo y el contexto, el artículo comienza con una breve discusión sobre el panorama socio-histórico en la adolescencia. A continuación, se analiza cómo la Gestalt-terapia, de acuerdo con sus supuestos teóricos más básicos - entre los que destaca la Teoría del Campo de Kurt lewin - resuena y, al mismo tiempo, ofrece nuevos matices a la crítica histórico-social, concibiendo la adolescencia como un fenómeno singular y de campo.

Palabras-clave: Adolescencia; Gestalt-Terapia; Psicología socio-histórica; Teoría de campo.

\section{Introdução}

O presente artigo pretende discutir a adolescência sob a perspectiva da Gestalt-terapia, entendendo-a como um fenômeno singular e de campo. Nesta direção, questionamos a concepção naturalizante presente em diversos estudos sobre a adolescência em que características de caráter supostamente universal são tomadas como condição natural deste período.

Para desenvolver tal argumento, o artigo estabelece uma articulação entre algumas leituras sobre a adoles- cência na ótica da psicologia sócio-histórica e o embasamento teórico da Gestalt-terapia. A escolha de tal rota teórica se justifica pela coerência entre tais abordagens no que tange à relação indivíduo-contexto.

A Psicologia Histórico-Cultural ou Sócio-Histórica fundada por Liev S. Vygotski na década de 1920 e desenvolvida por autores como Luria e Leontiev entende o indivíduo como um ser constituído nas condições concretas de sua existência. Sob inspiração do materialismo histórico dialético de Karl Marx, o indivíduo é concebido nesta abordagem como um ser ativo e histórico. Em outras 
palavras, como determinado e determinante da própria condição no interior de um dado contexto.

Similarmente, a Gestalt-terapia - refletindo dentre outros aspectos teóricos, a assimilação de certos pressupostos-chave da Teoria de Campo fundada por Kurt Lewin - vê o ser humano como um existente impossível de ser compreendido fora do contexto de suas relações, desde as mais elementares, com as pessoas de seu convívio, até as mais amplas, com a sociedade, a história, e o universo.

Em um artigo esclarecedor acerca das fontes epistemológicas do pensamento vigotskiano, Toassa e Souza (2010) sublinham algumas importantes afinidades teóricas entre Vigotski e Kurt Lewin. Dentre tais afinidades, as autoras destacam os conceitos de espaço vital e campo psicológico de Lewin de um lado, e o conceito vigotskiano de vivência, de outro. Segundo elas, a imersão do indivíduo em seu meio é destacada em ambos, superando concepções dualistas de outras psicologias nas quais uma cisão artificial entre meio e indivíduo é estabelecida.

Desde Lewin e Vigotski, portanto, pode-se dizer que a abordagem sócio-histórica e a Abordagem Gestáltica convergem no que tange a consideração dos fenômenos em sua totalidade, superando dualidades como interno/ externo, biológico/social, ontogênese/filogênese, psíquico/orgânico, homem/sociedade, dentre outras.

Reconhecendo tais ressonâncias, é necessário ressaltar, entretanto, que o presente estudo não almeja desenvolver uma articulação da ótica Sócio-Historica sobre a adolescência com a visão da Gestalt-terapia. Além de não ser o foco do artigo, tal proposta ultrapassaria em muito o espaço disponível.

É importante esclarecer ainda que acreditar na possibilidade de diálogo entre tais abordagens não implica sugerir que estas são congruentes em todos os seus aspectos teóricos e filosóficos. A própria afinidade teórica entre Lewin e Vigotski, por exemplo, não exclui a existência de diferenças importantes entre as suas teorias, o que se revela, por exemplo, na forte inspiração histórico-cultural, marxista, presente no pensamento de Vigotski e ausente nas idéias do primeiro. A inspiração marxista dota a ótica sócio-histórica de uma ênfase particular na idéia de dominação econômico-ideológica e política no interior da sociedade capitalista e de crítica a este sistema, ênfase esta que não faz sentido na Gestalt-terapia.

Além disso, embora afirmem o homem como multidimensional, determinado e determinante de sua condição, em algumas análises, a dimensão de determinação se sobrepõe ao reconhecimento e devida valorização da liberdade e singularidade humanas como entende a Gestalt-terapia. Ainda, o caráter fenomenológico da Gestalt-terapia a diferencia da perspectiva sócio-histórica que, numa inspiração vigotskiana, postula que a compreensão dos fenômenos só é possível a partir de uma explicação (e não "meramente" uma descrição) das relações que o determinam.
Muitas outras diferenças poderiam ser discutidas, mas como dito, não é este o espaço para tal. Nosso objetivo é, portanto, e tão somente, explorar e desenvolver a compreensão da adolescência na Abordagem Gestáltica como um fenômeno singular e de campo partindo de um diálogo com algumas leituras da abordagem sócio-histórica acerca do tema.

A afinidade de posicionamento teórico no que concerne, como mencionado anteriormente, à relação indivíduo-contexto torna tal articulação teórica não só possível como também bastante inspiradora para o entendimento do fenômeno da adolescência numa ótica gestáltica. Assim, se por um lado, a ênfase nas determinações sócio-históricas é rejeitada pela Gestalt-terapia, por outro lado, a ênfase oposta, nos aspectos biográficos do ser em contraposição aos aspectos mais amplos da pertença ao mundo social, cultural e econômico é outra maneira de também negligenciar partes e, portanto, de perder a visão de todo tão valorizada nesta abordagem. Como psicólogos e psicoterapeutas, sabemos que, na prática, o risco na direção de uma compreensão psicologizante do humano é sempre presente, embora também acreditemos que a fundamentação teórica da Gestalt-terapia nos protege disso. Assim, não só no sentido teórico, mas também no sentido pragmático, o diálogo com uma abordagem que sublinha o olhar sócio-histórico parece relevante.

\section{A Leitura Sócio-Histórica da Adolescência}

Conforme os estudos de Aguiar, Bock e Ozella (2001) a idéia hoje hegemônica sobre a adolescência é contemporânea ao surgimento da sociedade moderna industrial. Segundo os autores, é por meio da maior permanência dos jovens nas escolas e do correlato retardamento da profissionalização dos mesmos no interior de um determinado sistema sócio-cultural e econômico que se conforma a adolescência com as características que conhecemos hoje.

Discutindo a adolescência sob o ponto de vista da Psicologia Sócio-histórica, Facci e Tomio (2009) sugerem que uma indicação clara da conformação histórica da adolescência se revela no discurso das gerações anteriores. As autoras observam que pessoas nascidas por volta da década de 1940 e anteriormente, costumam declarar que "no seu tempo não havia adolescência", no sentido de um período intermediário entre a infância e a idade adulta. Tais discursos sugerem que há cerca de 80 anos, as pessoas passavam da condição de criança diretamente para a de adulto, processo este fortemente vinculado à presença do trabalho, principalmente no caso dos homens. No caso das mulheres, apontam as autoras, uma vez que estas eram chamadas a cuidar da casa ou mesmo de uma nova família (na medida em que se casavam bem mais cedo), este "período de latência" entre infância e vida adulta também não fazia sentido. Somente a partir 
da necessidade de prolongar o tempo de formação dos jovens - a fim de prepará-los para as novas as demandas de trabalho geradas pela industrialização emergente - que a idéia, os discursos e, em muitos sentidos, a própria experiência da adolescência começa a se constituir.

Um estudo de Clímaco (1991, conforme citado por Bock, 2007) ressalta que outro aspecto relevante na construção histórica da adolescência foi o impacto gerado pelo desenvolvimento científico sobre a prolongação da vida e o consequente aumento de adultos jovens em idade de trabalho. A partir disso, mais uma razão se colocava para aumentar o tempo de permanência nas escolas, pois, além da já citada demanda de formação mais sofisticada, a escolarização prolongada ajudaria a regular a alta taxa de desemprego dos estágios iniciais do desenvolvimento industrial.

Neste processo, os filhos passam a viver mais tempo sob a tutela dos pais, sem ingressar no mercado de trabalho, ao mesmo tempo em que surgem as oportunidades para que encontrem, na escola, os chamados "grupos de iguais". Com isso, apesar de ser possível assumir um papel diverso na sociedade (como acontecia no passado), o jovem se distancia do mundo do trabalho e das possibilidades de obter autonomia e condições de sustento. Estão lançadas, assim, as condições sociais que "convidam" os jovens a desenvolver uma série de características que, nos dias de hoje, são frequentemente concebidas como naturais (Bock, 2007).

Segundo a crítica sócio-histórica, com a qual concordamos, os discursos de caráter naturalizado sobre a adolescência devem ser revisitados. No domínio da Psicologia, sob influência da Psicanálise e da Epistemologia genética principalmente, uma visão naturalizante da adolescência é desenvolvida e se propaga por todo o ambiente cultural. Nesta ótica, a adolescência é decorrente, sobretudo, de um acelerado processo de mudanças biológicas e 'pulsionais' (por meio do despertar da sexualidade no nível da maturidade genital) que, por si só, acarretam as mudanças supostamente inerentes ao desenvolvimento adolescente (Facci \& Tomio, 2009).

Ao alienar a participação da cultura na conformação das visões e experiências da adolescência, tal perspectiva naturalizante subestima não apenas as raízes históricas do período como também os interesses subjacentes de mercado que se beneficiam de uma delimitação precisa de características, hábitos e interesses nesta época da vida.

Num artigo que trata da historicidade dos conceitos de infância e de adolescência, Frota (2007) cita diversos autores que analisam a interrelação entre adolescência e mercado. Abramo (1994, conforme citado por Frota, 2007), por exemplo, analisa que por volta da década de 1960, período em que os chamados movimentos estudantis e, portanto, os jovens, ganham grande projeção cultural, surge uma grande variedade de signos associados à cultura juvenil. Estes, sendo incorporados pelo mercado (em rápida evolução na época) e espetacularizados na lógica própria do marketing e dos meios de comunicação, ajudam a produzir novos traços para a identidade juvenil. Marcadas por imagens produzidas de "ser jovem" - muitas vezes associadas à rebeldia, contestação de regras e à busca do prazer - e pelo consumo de determinados bens e serviços, as identidades adolescentes vão então se constituindo. Nesse processo, em alguns níveis, a adolescência se torna um discurso de mercado que simultaneamente revela e produz visões e experiências de ser adolescente.

Tais raízes históricas são raramente levadas em consideração nos estudos clássicos sobre o tema. Ao invés disso, a adolescência tem sido tradicionalmente descrita como um período inerentemente problemático em que a irresponsabilidade, a rebeldia gratuita e as identificações massificadas com grupos e tribos predominam não como conseqüência de tais forças, mas como um efeito previsível numa adolescência dita normal.

Aguiar et al. (2001) sublinham o papel central da Psicanálise na construção desta perspectiva, em que a adolescência é tomada como uma fase inerentemente problemática a ser ultrapassada em direção à maturidade. Particularmente, afirmam os autores, diante da influência exercida pelo psicólogo Stanley Hall (introdutor da psicanálise nos Estados Unidos) a adolescência passa a ser concebida como uma etapa marcada por conturbações vinculadas à emergência da sexualidade.

Mais recentemente, Aberastury e Knobel (1992) reproduzem e disseminam tal concepção naturalizante. Na leitura dos autores, após tornar-se biologicamente capaz de exercer a sua genitalidade para a procriação, e vivenciar mudanças "incontroláveis" em seu corpo, instauram-se conflito referentes à diferença entre o corpo real e o corpo ideal e ainda quanto à própria definição da sexualidade, que não ocorre de imediato. Tal conflito fomenta reações de instabilidade afetiva, crises, conduta turbulenta ou de indiferença, angústias e ansiedades, configurando uma espécie de "patologia normal da adolescência".

Outro aspecto problemático das visões sobre a adolescência que vem sendo denunciadas pela perspectiva sócio-histórica diz respeito à postulação de características supostamente universais do período baseadas, na realidade, nas condições de adolescentes oriundos das classes médias e altas da sociedade.

Tais características e experiências, tomadas em análises pouco cuidadosas como generalizáveis, são, entretanto, plenamente situadas. Neste sentido, a singularidade das contradições e incertezas de adolescentes oriundos das classes populares, que pra começar, experimentaram infâncias bastante diversas, raramente é levada em consideração. Eles são adolescentes e isso parece dizer tudo. Será?

As pesquisas de Aguiar e Ozella (2008) sugerem que a resposta a esta pergunta deve ser um sonoro "não". 
Segundo os autores, muitos adolescentes das classes mais pobres da sociedade, contrariando a cartilha dos manuais de psicologia, não sofrem tanto com os tradicionalmente mencionados conflitos familiares na luta pela diferenciação e construção de si ou com as dúvidas quanto à escolha da carreira. Frequentemente, observam as autoras, suas dores se revelam, principalmente, em sua falta de perspectivas, no medo de ficarem desempregados e, mais do que pensar em escolher uma profissão, duvidam se poderão conseguir um trabalho.

Desse modo, se o adolescente vivencia um lugar social em que projetos de vida e até mesmo de sobrevivência estão em cheque, definir 'quem eu sou' pode ser mais do que uma manobra de discriminação em relação aos pais e outros adultos significativos. Em alguns casos, o campo em que se constituem impõe a necessidade de discriminar-se de um não-lugar na sociedade a fim de que outro lugar, possível, possa ser projetado.

\section{Perspectivas Gestálticas: Adolescência-no-Campo}

Ao investigar tais circunstâncias sobre o ponto de vista da Gestalt-terapia, constata-se, em primeiro lugar, que o questionamento acerca dos condicionantes contextuais da adolescência realizado pelos autores da abordagem sócio-histórica é bastante coerente com a perspectiva de relacional abraçada pela abordagem.

Como desenvolveremos a seguir, a Gestalt-terapia entende ser a concretude da existência do ser-no-mundo que se manifesta em cada adolescente. Tal concretude inclui, mas não se limita, nem se organiza a partir do aspecto fisiológico das mudanças corporais, como diversas abordagens teóricas pressupõem. Ser adolescente é, portanto, sê-lo num determinado corpo, mas também numa determinada sociedade, etnia, classe social, cultura, família e para determinada pessoa que vai significar todos estes aspectos de formas sempre únicas.

Desta maneira, a perspectiva evolucionista em que o desenvolvimento psicológico ocorre de maneira progressiva por meio de estágios fixos e invariáveis - adotada pelas teorias tradicionais sobre adolescência - deve ser contestada. Ao conceberem seres abstratos que atravessam os mesmos estágios, na mesma sequência, em direção à maturidade, tais teorias alienam pelo menos dois aspectos fundamentais da Abordagem Gestáltica: a concretude existencial dos existentes e sua singularidade. Concordamos então com as idéias de Antony (2006) e Soares (2005) quando sustentam que a compreensão do desenvolvimento segundo a Gestalt-terapia supera a visão reducionista e determinista do existir humano que compartimenta, fixa e normaliza as fases da vida

Na Gestalt-terapia, a idéia de seres concretos e situados é revelada desde a noção de campo-organismo-ambiente apresentada por Perls, Hefferline e Goodman (1951/1997) no livro inaugural da Gestalt-terapia:
Em toda e qualquer investigação biológica, psicológica ou sociológica temos de partir da interação organismo-ambiente. Não tem sentido falar, por exemplo, de um animal que respirar sem considerar o ar e o oxigênio como parte da definição deste, ou falar de comer sem mencionar a comida (...). Não há uma única função, de animal algum, que se complete sem objetos e ambiente (...). Denominemos esse interagir entre organismo e ambiente em qualquer função o 'campo organismo/ ambiente' e lembremo-nos de que qualquer que seja a maneira pela qual teorizamos sobre impulsos, instintos, etc., estamos nos referindo sempre a este campo interacional e não a um animal isolado (p. 42-43).

A Teoria de Campo de Kurt Lewin, embutida na definição gestáltica de campo-organismo-ambiente, introduz a idéia de que, psicologicamente, diversas forças e influências agem umas sobre as outras produzindo um resultado que é sempre único dentro de um tempo igualmente específico.

Em "Principles of Topological Psychology" (1936), Kurt Lewin explicita sua perspectiva acerca do papel do ambiente na vida individual, esclarecendo que este não deve ser tomado como uma força exterior que serve meramente para facilitar ou para inibir tendências prévias e definitivamente estabelecidas na natureza da pessoa.

Ora, é justamente essa a perspectiva tradicionalmente assumida pelas teorias psicológicas do desenvolvimento ao abordarem a adolescência. De acordo com tais teorias, o homem é dotado de uma natureza e suas relações com o meio apenas permitem (ou dificultam) a atualização de tais traços naturalmente dados.

Segundo o estudo de Muuss (1996), Kurt Lewin apresenta sua teoria da adolescência em trabalho intitulado "Teoria de campo e experimento na psicologia social" (Lewin, 1939, citado por Muuss, 1996), fornecendo alguns elementos importantes para pensar a adolescência na perspectiva gestáltica.

Um aspecto fundamental do pensamento lewiniano nesta área é sua crítica de conceitos psicológicos baseados na frequência com que ocorrem numa população dada. Segundo Lewin (1939, conforme citado por Muuss, 1996) na medida em que leis psicológicas são abstraídas a partir do comportamento de muitos s, elas só podem ser verdadeiras em termos de probabilidade. A análise de Kurt Lewin sobre adolescência se propõe, portanto, a explicar e a descrever a dinâmica de comportamento de quem vivencia o período sem apostar numa generalização possível para a adolescência enquanto grupo.

Tal observação é muito oportuna e bastante congruente com a perspectiva teórica e filosófica da Abordagem Gestáltica bem como com o argumento principal do presente artigo. Assim, embora as teorias psicológicas se refiram a comportamentos e sentimentos possíveis e por vezes freqüentes, estes são equivocadamente transfor- 
mados em leis psicológicas gerais e, portanto, naturais e intrínsecas ao desenvolvimento humano.

Lewin chama atenção para a dificuldade de nomear a interação indivíduo-ambiente sem isolar cada elemento do par. Para dar conta deste problema, o autor introduz o termo "espaço de vida psicológico" que indica, segundo ele, a totalidade dos fatos que afeta o comportamento de uma pessoa num certo momento (Lewin, 1936). Essa totalidade dos fatos cria um campo dinâmico, o que significa que uma mudança numa das partes afeta todas as demais partes e o campo como um todo.

Embora na visão de Kurt Lewin a adolescência seja vista como um fenômeno sempre diferenciado para cada pessoa, algumas regularidades são apontadas por ele no que concerne às transformações que ocorrem no espaço de vida do jovem. No período da adolescência, observa Lewin (1939, citado por Muuss, 1996), este se torna mais extenso e mais diferenciado em comparação ao espaço de vida mais restrito e pouco diferenciado da criança. $\mathrm{O}$ adolescente conhece mais pessoas, torna-se familiar com mais áreas geográficas, informações, ou seja, têm maiores recursos cognitivos, sociais, físicos e de linguagem para contatar o ambiente e a si mesmo. Muuss (1996) ressalta, entretanto, que na proposta lewiniana, uma compreensão acurada de tais novidades precisa levar em consideração o caráter dinâmico e sempre particular do ambiente no qual as mudanças ocorrem e, ainda, as diferentes formas de sensibilidade e modos de ação.

Isso significa que pra Lewin o ambiente não é somente a totalidade dos fatos presentes, mas inclui, também, o ambiente tal como é percebido e interpretado pela pessoa, de acordo com suas próprias necessidades do momento. Como analisa Evangelista (2010), o "meio" na Teoria de Campo é o "meio fenomenológico", isto é, o ambiente tal como a pessoa o experimenta e não como uma presença objetiva. Neste sentido, verifica-se que a concepção gestáltica de indivíduo relacional e singular ressoa desde as idéias lewinianas, perspectiva esta que reconhecidamente influenciou a constituição da Gestalt-terapia.

Vale sublinhar, ainda, que a idéia de campo na Gestalt-terapia vai além das definições propostas por Lewin. Como colocado acima, a Teoria de Campo é apenas uma das fontes na qual a Gestalt-terapia foi "beber" para construir a formulação própria desta abordagem. Deste modo, além de elementos da Teoria do Campo, esta integra (e transforma) elementos da Teoria Organísmica, da Psicologia da Gestalt e das concepções filosóficas do Humanismo, Existencialismo e da Fenomenologia.

Inclusive, algumas análises (por exemplo, Evangelista, 2010) sugerem que ao recorrer ao modelo da física, a Teoria de Campo tende a objetificar o ser humano entendendo-o a partir das mesmas leis que regem objetos físicos. Tal concepção, segundo o autor, se choca com a ótica fenomenológica, baseada na idéia de que as pessoas devem aparecer para a compreensão do psicólogo a partir de sua humanidade e não a partir de leis objetivas mecânicas como postula a teoria de Lewin.

Embora não caiba aqui uma análise mais amiúde de tal posicionamento critico, vale destacar que não apenas a teoria lewiniana, mas diversos outros elementos - filosofias ou teorias que fundamentam a Abordagem Gestáltica - compõem a visão gestáltica da noção de campo. Deste modo, uma compreensão “de campo" que supera as mencionadas dicotomias entre indivíduo/sociedade e outras marca a Gestalt-terapia para além da influência de Lewin, pautando-se na própria natureza holística da abordagem. É isso que leva Antony e Ribeiro (2005) a afirmarem que de acordo com as suas teorias de base, "a Gestalt-terapia fundou uma visão holística calcada no conceito todo-parte, onde somente a totalidade contém o significado a partir das múltiplas interações existentes entre as partes e os campos (...)" (p. 193).

Isso sugere uma visão de adolescência como um fenômeno global que integra "num todo singular" as diversas forças do ser-no-campo e não como mera latência em direção à maturidade. Como resume Almeida (2010, p. 19), "estamos, a todo instante, imersos em uma complexidade infindável de estímulos, vivências, experiências que não podem ser restritas a uma linha do tempo" dotando a visão de desenvolvimento na Gestalt-terapia de uma perspectiva oposta à idéia de amadurecimento tão comumente adotada pelas abordagens de desenvolvimento. Aguiar (2005) também aborda a questão, destacando que ao conceber o homem como um todo singular em constante transformação na busca de equilíbrio (equilíbrio este ora perturbado, ora recuperado numa articulação entre necessidades e possibilidades no campo) a Gestalt-terapia não pode pensar o ser - na lógica da universalidade - como um projeto inacabado ou imperfeito que viria a se concretizar na fase adulta.

Neste ponto, alguém poderia argumentar que um aspecto universalmente presente na adolescência são as transformações físicas sofridas pelo corpo neste período da vida. De fato, as mudanças físicas são marcas concretas desta fase. No entanto, o corpo não é entendido, na Gestalt-terapia, em relação de exterioridade em relação aos domínios subjetivos e relacionais. Assim sendo, embora as mudanças físicas sofridas pelo adolescente tenham um caráter objetivo enquanto "marcas" no corpo, estas são necessariamente significadas pelo ser-no-campo.

Nesta direção, Perls (1988) observa que a partir da perspectiva de campo que marca a Gestalt-terapia, não faz qualquer sentido entender as ações mentais e físicas de forma cindida. Portanto, a tentativa de encontrar um padrão geral nos supostos "fatos objetivos" do corpo (o que contrariaria a concepção de adolescência como fenômeno sempre singular e de campo) não se sustenta.

O Gestalt-terapeuta norte-americano McConville (2001), apoiando-se nos estudos de Kurt Lewin, conce- 
be a adolescência como uma desestruturação da unidade da infância por meio da expansão do espaço de vida e da transformação dos processos de contato que organizam o campo.

Para entender esta afirmação, é necessário fazer, neste ponto, uma breve introdução ao conceito de contato na Gestalt-terapia. Contato envolve tanto a noção de self quanto a de campo, referidas anteriormente. Segundo Perls et al. (1951/1997): "Primordialmente o contato é a awareness da novidade assimilável e o comportamento em relação a esta e rejeição da novidade inassimilável. $O$ que é difuso, sempre o mesmo, ou indiferente, não é objeto de contato" (p. 44). Mais adiante, continuam os autores: "Todo contato é ajustamento criativo do organismo e ambiente. Resposta consciente no campo (como orientação e como manipulação) é o instrumento de crescimento no campo" (p. 45).

A presença da novidade na adolescência é, em muitos aspectos, notável. Neste período, o adolescente começa a se defrontar com a necessidade de definir a sua vida diante das novas questões existenciais como as que se depara - concernentes a sua sexualidade, os seus estudos, relacionamentos de amizade, escolha da carreira e tantas outras, que demandam decisões íntimas (McConville,1995). Por consequência, este é um período do desenvolvimento no qual a capacidade de contato, que se desenvolve durante toda a vida, é vivida de maneira intensa e significativa.

Neste sentido, conforme McConville (1995), a fronteira de contato do adolescente - limite que contém e protege o organismo ao mesmo tempo em que contata o ambiente (Perls et al., 1951/1957) - está se constituindo, amadurecendo e sendo burilada diante dos novos desafios.

Em termos concretos, ainda segundo McConville (1995), quando criança, vivencia-se uma relação de dependência vinculante com os adultos no qual boa parte de seu espaço de vida é indiferenciado do espaço de vida adulto. Cabe aos adultos, por exemplo, a maior parte senão todas - as decisões a respeito de suas atividades, como por exemplo, a escolha de sua escola, métodos pedagógicos, aceitação de professores, tipo de alimentação, de diversão e programas culturais, atividades educativas extra-escolares etc. O padrão relacional estabelecido na infância é, fundamentalmente, jogar, obedecer, aprender e depender enquanto na adolescência, o caminho é em direção à independência.

Problematizando a descrição de McConville e, ao mesmo tempo, ressaltando a dimensão de campo deste processo, é interessante observar que sua análise faz sentido no interior de um contexto cultural dado - o das sociedades ocidentais contemporâneas ${ }^{1}-\mathrm{e}$, de forma privilegiada, melhor se ajustam a determinados segmentos

\footnotetext{
Ressaltamos que o próprio contorno do termo "sociedades ocidentais contemporâneas" como uma unidade evidente e indiferenciada é bastante contestável, o que se revela, no campo sociológico, por meio da noção de "múltiplas modernidades" (Eisenstadt, 2000).
}

sócio-culturais no interior dessa. De fato, na tentativa de aplicar tal descrição à realidade de crianças oriundas de segmentos pobres de nossa sociedade, contradições significativas emergem. Assim, embora uma criança não vá, por exemplo, escolher uma escola discernindo sobre os métodos pedagógicos, muitas crianças, assumindo a tarefa de cuidarem dos irmãos mais novos precisam se responsabilizar e tomar decisões desde muito cedo. Desse modo, sua experiência de depender, embora não seja nula, é certamente diferenciada para este público.

Além disso, embora seja possível dizer que, na infância, a criança está mais disposta a receber informações de maneira passiva ela definitivamente não é um mero receptor de princípios adultos. A depender das condições gerais do campo (incluindo aspectos familiares, culturais, históricos, educacionais e outros) e da singularidade de cada criança, o questionamento e a escolha farão parte de suas interações na vida. Nesta linha de argumentação, Aguiar (2005) ressalta o surgimento da capacidade de diferenciação ainda na infância, quando a criança é capaz de rejeitar ou digerir determinada introjeção familiar, iniciando o processo de constituição de sua fronteira de contato, processo esse que continuará a se aperfeiçoar ao longo do tempo.

Ainda, levando em conta o campo sócio-cultural que caracteriza as sociedades contemporâneas - em que as antigas autoridades tradicionais têm seu poder diluído e, dentre outros aspectos, o antigo abismo de poder entre as gerações é questionado - as crianças dos dias de hoje também "são outras". Cada vez mais, elas perguntam, questionam e por vezes "colocam os pais em cheque", apontando-lhes contradições e até mesmo questionando seus valores (comportamento anteriormente tipicamente esperado apenas com a chegada da adolescência). Assim, diante das complexidades do mundo contemporâneo, em que a antiga força e rigidez da palavra dos pais são diluídas diante da coexistência de múltiplos referenciais de sentido (Berger \& Luckmann, 1995) é cada vez mais freqüente que os pais / responsáveis se sintam perdidos e fragilizados diante da necessidade de impor limites e mesmo diante da necessidade de se diferenciar, em termos de papel, das crianças.

Quanto à adolescência, jovens das classes populares se depararam com questões por vezes bastante diversas das de um jovem típico da classe média.

Isso não significa, entretanto, que a condição sócio-econômica determina a adolescência de uma forma totalizante estabelecendo uma espécie de "classificação" de características da adolescência de acordo com as condições materiais. Na ótica gestáltica, o que muda são as forças presentes no campo, o que certamente afeta, mas de modo algum determina o comportamento e as experiências dos jovens.

No que diz respeito à dimensão tempo, (que precisa ser sempre levada em consideração numa abordagem "de campo" como a Gestalt-terapia) a época contemporânea 
introduz diversas transformações na experiência de ser adolescente.

Como diversas análises têm ressaltado (ver por ex.: Lira, 2010; Garcia \& Rocha, 2008; Calligaris, 2000), o antigo anseio de se tornar adulto, escolher uma profissão, assumir responsabilidades, constituir família etc. vêm sendo permeado por aspectos contraditórios.

Se por um lado é provável que tais anseios ainda existam, por outro, eles convivem com a valorização da adolescência como ideal cultural (Garcia \& Rocha, 2008). Isso se revela em circunstâncias nas quais a antiga e tradicional versão cultural em que adolescentes querem parecer e ter os direitos e liberdades dos adultos aparece de forma invertida. Atualmente, numa cultura em que a liberdade, o prazer e a juventude (de corpo e espírito) são propagados como instrumentos de valor pessoal ou até mesmo como imperativos sociais é cada vez mais comum encontramos adultos querendo ter direitos e liberdades de adolescentes.

Deste modo, falar em conflitos de gerações, ou mesmo descrever a adolescência como uma transição para o mundo adulto, pode significar cair no vazio. O vazio é gerado pela falta de sensitividade para os elementos de-um-campo que como analisamos anteriormente, é sempre mutante no tempo e no espaço.

\section{3. "Liberdade" e "Campo": Facetas Inextrincáveis no Conceito de Ajustamento Criativo}

O conceito gestáltico de ajustamento criativo, absolutamente conectado ao conceito de contato e de campo referidos anteriormente, constitui um elemento central da visão gestáltica sobre processos de saúde e doença, sendo, portanto, fundamental para a compreensão do desenvolvimento humano nesta abordagem.

Por meio da capacidade humana de ajustar-se criativamente ao meio, ao mesmo tempo em que o ser se constitui nas facticidades do desenvolvimento biológico, da cultura, da classe social e da época em que vivemos, pode lidar criativamente com isso, escolhendo e criando a si mesmo continuamente.

O ajustamento criativo pode ser definido como o processo pelo qual o existente se relaciona com o meio criativamente na busca de equilíbrio através dos recursos disponíveis no campo (Ribeiro, 2006). Ou ainda, como define Moreira (2010, p. 24): “Ajustamento criativo significa auto-regulação, abertura ao novo, contato vivo e vitalizante, referindo-se à formação de novas configurações pessoais (ou gestalten) a partir da entrada de novos elementos através da experiência de contato”. Portanto, tal processo configura-se como uma expressão do ser-no-campo, no qual as facetas humanas de liberdade (revelado na palavra criativo) e contextualidade (sentido presente na palavra ajustamento) atualizam-se de maneira integrada.
No caso particular do adolescente, este fará então o possível para equilibrar-se diante da circunstância em que se encontra num balanço entre possibilidades presentes de si mesmo e do contexto. Alguns ajustamentos podem, portanto, revelar respostas fluidas e espontâneas às suas novas necessidades. Por outro lado, alguns ajustamentos podem indicar um modo rígido e pouco respondente às mudanças enfrentadas.

Assim, se o trânsito entre a vivência do "campo infantil” para o "campo adolescente" pode, por um lado, constituir uma experiência de crise, por outro, a busca pelo projeto de si mesmo pode assemelhar-se mais a uma progressiva exploração de papéis e potenciais escolhas (que pode inclusive ter começado paulatinamente desde a infância) do que uma repentina busca sofrida e angustiada por si mesmo.

Tradicionalmente, enquanto o aspecto de regularidade das tormentas emocionais e crises adolescentes é, repetidamente, objeto de análise em diversas teorias sobre o desenvolvimento, outros aspectos, como a visão crítica, a amizade, a sinceridade e até a lucidez adolescente que a chamada maturidade frequentemente amortece são raramente mencionados. Sendo a Gestalt-terapia uma abordagem que concebe o indivíduo como um ser relacional, transformador e único, a generalização ou universalização de supostas características da adolescência, bem como a exclusão de outras formas possíveis de se ajustar criativamente devem ser evitadas.

Para finalizar, vale destacar um elemento fundamental do contexto do adolescente que afetará de modo importante seu processo de ajustamento criativo: seu relacionamento com os "outros significativos" (pais, responsáveis, professores, familiares, amigos etc.).

Se na criança o relacionamento com os familiares e adultos se caracteriza, predominantemente, por uma dependência vinculante, a partir das diversas mudanças no espaço de vida dos jovens, estes tendem a sentir a necessidade de serem tratados como indivíduos separados e independentes. Consequentemente, se perceberem ser necessário, podem se ajustar criativamente à nova situação materializando um jogo de oposições com seus responsáveis, contrariando opiniões, idéias e valores dos mesmos a fim de construir sua própria forma de ser.

Em algumas experiências, é possível que os responsáveis e familiares rivalizem com os adolescentes, ou sigam tratando-os como crianças para, desta forma, negar a passagem do tempo e a finitude de seu poder e primazia sobre eles. Nestes casos, o campo como um todo está impregnado de elementos de conflito, e não apenas o adolescente, como se este existisse isolado em uma suposta interioridade conflituosa.

Por outro lado, tais padrões de relacionamento com a família também não devem ser naturalizados. Relações conflituosas com pais e responsáveis têm sido tão amplamente generalizadas nas leituras acadêmicas e no imaginário social sobre adolescência que algumas famílias 
desconfiam que algo possa estar errado caso o adolescente mantenha-se responsável, lúcido e uma companhia agradável. No entanto, a diferença humana ainda resiste às generalizações teóricas e alguns adolescentes efetivam ajustamentos criativos num campo em que a proximidade e o diálogo com a família podem se desenvolver sem afetar sua necessidade de discriminação.

De qualquer modo, o comportamento do adolescente revela o que vive na escola, na família, na sociedade e na cultura. Em vários níveis, insistimos, ele não é adolescente sozinho. Na perspectiva de campo adotada pela Gestalt-terapia, cada existente co-existe numa realidade compartilhada em que todos estão implicados (Parlett, 2005). Entretanto, se é verdade que o adolescente não vivencia seus possíveis conflitos de modo interno, mas num campo, por outro lado, a família, a escola ou a sociedade também não são as causadoras por excelência de problemas na adolescência.

O existente (e, consequentemente, o adolescente) é para a Gestalt-terapia, produto e produtor de sua condição. Revelando a noção de causalidade circular da Gestaltterapia, a escola, a família, o mundo e o adolescente livre se influenciam mutuamente de modo a se tornar basicamente impossível detectar relações mecânicas de causa e efeito em suas interações (Brafman, citado por Toman e Bauer, 2005).

\section{Considerações Finais}

Como pretendemos ter deixado claro ao longo do artigo, a Gestalt-terapia compartilha o questionamento - que vem sendo explorado na literatura sobre o tema, sobretudo, pela perspectiva sócio-histórica - acerca da naturalização da adolescência como um fenômeno abstrato e universal.

Tal naturalização entra em choque com elementos fundamentais da concepção gestáltica de indivíduo, notadamente a consideração deste como um ser contextualizado (ser-no-campo) e singular e, portanto, como um existente que só pode ser compreendido no interior de suas relações sempre complexas e únicas com o mundo.

Sendo assim, podemos resumir dizendo que a leitura sobre a adolescência na ótica da Gestalt-terapia precisa ser flexível e complexa o suficiente para evitar os seguintes “engodos" teóricos: a naturalização do desenvolvimento adolescente, alienando aspectos históricos e contextuais inerentes a este; a correlata generalização e universalização de características que alienam a singularidade de cada experiência no mundo concreto; e, finalmente (aspecto esse que inclui os dois últimos), faz-se fundamental evitar a cegueira conceitual que reproduz entendimentos teóricos sobre a adolescência que se tornaram hegemônicos tanto na academia como no imaginário social, ignorando os aspectos reducionistas e estáticos embutidos em tais entendimentos que contrariam os pressupostos elementares da Gestalt-terapia.

\section{Referências}

Aberastury, A., \& Knobel, M. (1992). Adolescência normal: um enfoque psicanalítico. (S. M. G. Ballve, Trad.). Porto Alegre: Artes Médicas (Original publicado em 1970).

Aguiar, L. (2005). Gestalt-terapia com crianças: teoria e prática. São Paulo: Livro Pleno.

Aguiar, W. M. J., Bock, A. M. B., \& Ozella, S. (2001). A orientação profissional com adolescentes: um exemplo de prática na abordagem sócio-histórica. Em M. B. Bock, M. da G. M. Gonçalves \& O. Furtado (Orgs.), Psicologia sócio-histórica: uma perspectiva crítica em Psicologia (pp. 163-178). São Paulo: Cortez.

Aguiar, W. M. J., \& Ozella, S. (2008). Desmistificando a concepção de adolescência. Cadernos de Pesquisa, 38(133), 97-125.

Almeida, J. M. T. de. (2010) Reflexões sobre a prática clínica em Gestalt-terapia: possibilidades de acesso à experiência do cliente. Revista da Abordagem Gestáltica, 16(2), 217-221.

Antony, S. (2006). A criança em desenvolvimento no mundo: um olhar gestáltico. Revista IGT na rede, 3(4).

Antony, S., \& Ribeiro, J. P. (2005). Hiperatividade: doença ou essência. Um enfoque da Gestalt-terapia. Revista Psicologia Ciência e Profissão, 25(2), 186-197.

Berger, P. L., \& Luckmann, T. (1995). Modernity, Pluralism and Crisis of Meaning. Gütersloh: Bertelsmann Foundation Publishers.

Bock, A. M. (2007). A adolescência como construção social: estudos de livros destinados a pais e educadores. Psicologia Escolar Educacional, 11(1), 63-76.

Calligaris, C. (2000). A adolescência. São Paulo: Publifolha.

Eisenstadt, S. N. (2000). Multiple Modernities. Daedalus, 129(1), 1-29.

Evangelista, P. (2010). Interpretação Crítica da teoria de Campo Lewiniana a partir da Fenomenologia. Artigo elaborado para o Centro de Formação e Coordenação de Grupos em Fenomenologia. Disponível na World Wide Web: http:// www.fenoegrupos.com/JPM-Article3/index.php?sid=14

Facci, M. G. D., \& Tomio, N. A. O. (2009). Adolescência: uma análise a partir da psicologia sócio-histórica. Rev. Teoria e Prática da Educação, 12(1), 89-99.

Frota, A. M. M. C. (2007). Diferentes concepções da infância e adolescência: a importância da historicidade para sua construção. Estudos e Pesquisas em Psicologia, 7(1), $147-160$.

Garcia, C. A., \& Rocha, A.P. R. (2008). A Adolescência como Ideal Cultural Contemporâneo. Psicologia Ciência e Profissão, 28(3), 622-631.

Lewin, K. (1936). Principles of topological psychology (F. Heider e G. M. Heider, Trads.). New York: McGraw-Hill. 
Lira, N. T. S. (2010). Adolescentes e adultescentes na contemporaneidade. Revista IGT na Rede, 7(12), 24-25.

McConville, M. (1995). Adolescence: Psycotherapy and the emergent self. San Francisco: Jossey-Bass.

McConville, M. (2001). Lewinian field theory, adolescent development, and psychotherapy. Em M. McConville \& G. Wheeler (Eds.), The heart of development: Gestalt approaches in working with children, adolescents and their worlds: Vol. 2. Adolescence (pp. 26-53). Hillsdale, NJ: Analytic Press.

Moreira, V. (2010). Convergências e divergências entre as psicoterapias de Carl Rogers e Frederick Perls. Revista do Nufen, 01(1), 20-50.

Muuss, R. E. (1996). Theories of Adolescence. New York: McGraw-Hill.

Parlett, M. (2005). Contemporary Gestalt Therapy: Field theory. Em A. L. Woldt \& S. M. Toman (Eds.), Gestalt therapy History, Theory, and Practice (pp. 41-63). California: Sage Publications.

Perls, Fritz. (1988). A Abordagem Gestáltica e Testemunha Ocular da Terapia. (José Sanz, Trad.) Rio de Janeiro: LTC (Original publicado em 1973).

Perls, F., Hefferline, R., \& Goodman, P. (1997). Gestalt-terapia (F. R. Ribeiro, Trad.). São Paulo: Summus (Original publicado em 1951).
Ribeiro, J. P. (2006). Vade-mécum de Gestalt-Terapia: conceitos básicos. São Paulo: Summus.

Soares, L. L. M. (2005). Um convite para pensar sobre desenvolvimento em Gestalt-terapia. Revista IGT na Rede, 2(3).

Toassa, G., \& Souza, M. P. R. de. (2010). As vivências: questões de tradução, sentidos e fontes epistemológicas no legado de Vigotski. Psicologia USP, 21(4), 757-779.

Toman, S. M., \& Bauer, A. (2005). Adolescents: Development and Practice from a Gestalt orientation. Em A. L. Woldt \& S. M. Toman (Eds.), Gestalt therapy History, Theory, and Practice (pp. 179-199). California: Sage Publications.

Lauane Baroncelli - Psicóloga; Mestre em Psicossociologia de Comunidades e Ecologia Social pela Universidade Federal do Rio de Janeiro (UFRJ); Doutoranda em Sociologia pela University College Cork e Membro do corpo docente do Dialógico Núcleo de Gestalt-terapia (Rio de Janeiro). Endereço Institucional: O’Donovan’s Road, Department of Sociology, University College Cork, Cork, Ireland. Email: lauaneb@gmail.com

Recebido em 14.03 .12

Primeira Decisão Editorial em 26.09.12

Aceito em 10.11 .12 